\title{
Specific Therapy of Olfactory Disorders in COVID-19 Patients is Essential for the Prevention of Long-term Dysfunction
}

\author{
Luigi Angelo Vaira ${ }^{1,2}$ (1) $\cdot$ Jerome R. Lechien ${ }^{3,4} \cdot$ Stefano Dore $^{5} \cdot$ Riccardo Boccaletti $^{6}$. \\ Sven Saussez ${ }^{3,4} \cdot$ Giacomo De Riu $^{1,2}$
}

Received: 18 April 2021 / Accepted: 16 May 2021 / Published online: 22 August 2021

(C) The Author(s) 2021

Keywords Covid-19 · Anosmia $\cdot$ Smell disorders · Corticosteroids $\cdot$ Coronavirus $\cdot \mathrm{SARS}-\mathrm{CoV}-2 \cdot$ Therapy

\section{Dear Editor,}

We enjoyed reading the article by Borah et al. [1], recently published in your journal. The authors, starting from an extensive analysis of the otolaryngological symptoms of 2000 patients with a confirmed diagnosis of coronavirus disease 2019 (COVID-19), try to provide some general indications on the management of these patients. In this series of patients, a significant prevalence of olfactory and gustatory disorders was reported and, on this basis, the authors rightly suggest the opportunity to identify specific therapies for patients presenting these problems. The

Luigi Angelo Vaira

lavaira@uniss.it

1 Maxillofacial Surgery Unit, Department of Medical, Surgical and Experimental Sciences, University of Sassari, Viale San Pietro 10, 07100 Sassari, Italy

2 Biomedical Science Department, PhD School of Biomedical Science, University of Sassari, Sassari, Italy

3 COVID-19 Task Force of the Young-Otolaryngologists of the International Federations of Oto-Rhino-Laryngological Societies (YO-IFOS), Paris, France

4 Department of Human and Experimental Oncology, Faculty of Medicine UMONS Research Institute for Health Sciences and Technology, University of Mons (UMons), Mons, Belgium

5 Ophthalmology Operative Unit, Department of Medical, Surgical and Experimental Sciences, University of Sassari, Sassari, Italy

6 Neurosurgery Operative Unit, University Hospital of Sassari, Sassari, Italy authors' intent must be commended and we would like to enrich the debate raised by this article with some information that emerged from the experience we have gained in recent months on olfactory disorders in COVID-19 patients.

First, the need to implement specific therapies is confirmed by the fact that the first prospective studies with long-term follow-up are finding the persistence of severe olfactory disturbances in 5.5-11\% of patients 6 months after infection $[2,3]$. Such a high frequency, given the high prevalence of infection in the general population, means that in the near future we will have a huge number of patients with long-term morbidity seeking assistance.

The first pathological studies in patients with long-term COVID-19 related anosmia revealed an inflammatorybased destruction of the olfactory epithelium (OE) with involvement of the basal cells and loss of the regenerative potential of the OE [4]. Although in most patients this inflammation allows the regeneration of the $\mathrm{OE}$ and the recovery of the sense of smell within a few weeks, in some cases the inflammatory process can persist even after the resolution of the infection, progressively and irreparably damaging the OE. Unfortunately, the risk factors for the development of a long-term olfactory disorder have not yet been identified.

However, these recent pathogenic findings have provided the rationale for the use of systemic and local corticosteroids for the treatment of persistent COVID-19 related olfactory disorders [5]. This specific therapy is all the more effective the earlier it is started. Considering that the use of corticosteroids in patients with mild and moderate COVID-19, we believe it is indicated to postpone the initiation of therapy after the nasopharyngeal swab become negative. Future studies will be needed to establish safety 
and the opportunity of starting corticosteroid therapy earlier.

Acknowledgements None declared

Funding Open access funding provided by Università degli Studi di Sassari within the CRUI-CARE Agreement.

\section{Declarations}

Conflict of interest The authors declared that they have no conflict of interest.

Open Access This article is licensed under a Creative Commons Attribution 4.0 International License, which permits use, sharing, adaptation, distribution and reproduction in any medium or format, as long as you give appropriate credit to the original author(s) and the source, provide a link to the Creative Commons licence, and indicate if changes were made. The images or other third party material in this article are included in the article's Creative Commons licence, unless indicated otherwise in a credit line to the material. If material is not included in the article's Creative Commons licence and your intended use is not permitted by statutory regulation or exceeds the permitted use, you will need to obtain permission directly from the copyright holder. To view a copy of this licence, visit http://creativecommons. org/licenses/by/4.0/.

\section{References}

1. Borah H, Das S, Goswami A (2021) Otorhinolaryngological manifestations and its management in COVID 19 patients. Indian J Otolaryngol Head Neck Surg. https://doi.org/10.1007/s12070021-02436-9

2. Boscolo-Rizzo P, Menegaldo A, Fabbris C, Spinato G, Borsetto D, Vaira LA et al (2021) Six-month psychophysical evaluation of olfactory dysfunction in patients with COVID-19. Chem Senses. https://doi.org/10.1093/chemse/bjab006

3. Petrocelli M, Cutrupi S, Salzano G, Maglitto F, Salzano FA, Lechien JR et al (2021) Six-month smell and taste recovery rates in COVID-19 patients: a prospective psychophysical study. J Laryngol Otol. 135:436-441

4. Vaira LA, Hopkins C, Sandison A, Manca A, Machouchas N, Turilli D et al (2020) Olfactory epithelium histopathological findings in long-term coronavirus disease 2019 related anosmia. J Laryngol Otol 124:1123-1127

5. Vaira LA, Hopkins C, Petrocelli M, Lechien JR, Cutrupi S, Salzano G et al (2021) Efficacy of corticosteroid therapy in the treatment of long-lasting olfactory disorders in COVID-19 patients. Rhinology 59:21-25

Publisher's Note Springer Nature remains neutral with regard to jurisdictional claims in published maps and institutional affiliations. 